\title{
Microcephaly, mental retardation, cataracts, and hypogonadism in sibs: Martsolf's syndrome
}

\author{
M G HARBORD, M BARAITSER, AND J WILSON \\ The Hospitals for Sick Children, Great Ormond Street, London WC1N $3 J H$.
}

SUMMARY The association of microcephaly, mental retardation, cataracts, and hypogonadism is described in sibs (brother and sister) of consanguineous parents. These features are consistent with a diagnosis of Martsolf's syndrome. In addition, one sib had a cardiomyopathy while the other had cardiac failure.

The association of microcephaly, mental retardation, cataracts, and hypogonadism was first reported in 1978 by Martsolf et al in two brothers who were the offspring of first cousin Polish-Jewish parents. The two boys were said to look alike facially in that both had pouting lower lips, flat malar areas, and relative prognathism. In a further case report, ${ }^{2}$ two brothers whose parents were unrelated Sephardic Jews had microcephaly, mental retardation, cataracts, and hypogonadism, but looking at the pictures the dysmorphic facial features were minor, and it seems unlikely that there is an easily recognisable facial gestalt. Strisciuglio $e t \mathrm{al}^{3}$ described one male patient of non-Jewish ancestry who also had microcephaly, mental retardation, cataracts, and cryptorchidism, but who had few of the other features mentioned in the earlier reports. Recently, a brother and sister pair have been reported by Hennekam et al. ${ }^{4}$ We report a further brother and sister pair with the cardinal features in order to emphasise the recessive nature of the condition, to compare the facial dysmorphology with the pictures already published, and to suggest that the combination of features might be common to more than one syndrome.

\section{Case reports}

CASE 1

The parents were originally from Pakistan and are

Received for publication 3 August 1988

Revised version accepted for publication 12 December 1988. related, in that the father's grandmother and the mother's father were brother and sister (fig 1). The youngest child, a female (IV.6, fig 2) was born at term, after a normal pregnancy and delivery. Her birth weight was $2800 \mathrm{~g}$ and she was discharged from hospital after five days, only to be readmitted at 10 days of age because she was jittery. On examination, her head circumference was $34 \mathrm{~cm}$ which was on the 10th centile and consistent with her weight. She had brisk tendon reflexes but no clonus, and fundoscopy was normal. No cause for the jitteriness was found.

Obvious developmental delay was apparent by 10 weeks of age with hypotonia, no smile response, and poor visual attention. Seizures started at eight months of age, and at this time central lens opacities were apparent.

When reviewed at nine months, she was unable to lift her head or sit up and did not reach out for toys. She did not smile and was unable to fix or follow visual lures but responded to auditory stimuli.

$\mathbf{I}$

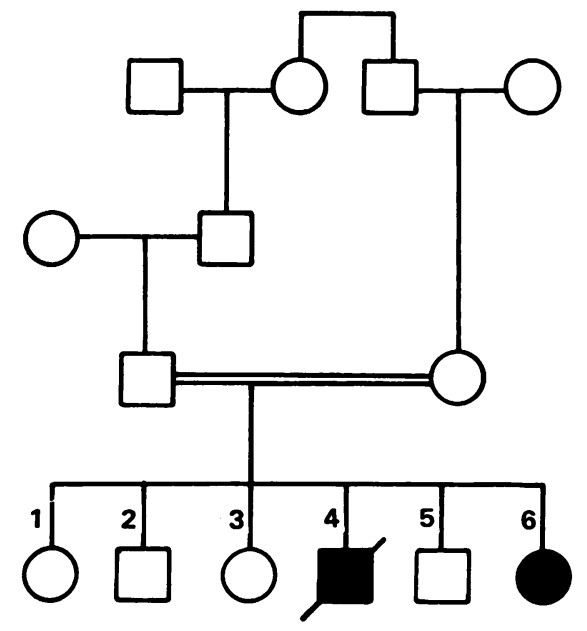

FIG 1 Pedigree of family. 
Her head circumference $(39.7 \mathrm{~cm})$ and her weight $(6.5 \mathrm{~kg})$ were below the 3 rd centile, while her length $(67 \mathrm{~cm})$ was on the 5 th centile. Tendon reflexes were still brisk and plantar responses were extensor, while she had marked head lag and poor bulbar

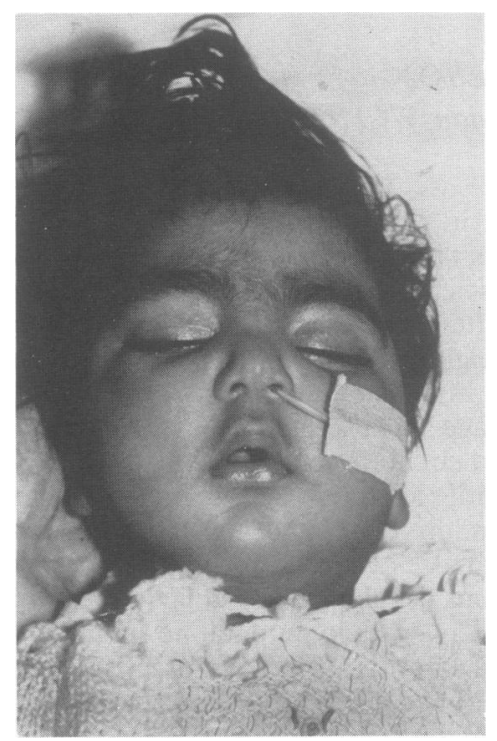

FIG 2 Case 1 (IV.6) at nine months of age.

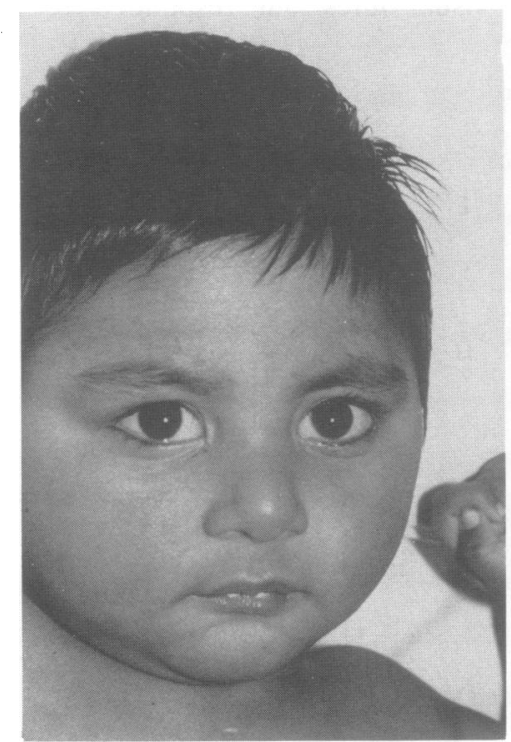

FIG 3 Case 2 (IV.4) at 18 months of age. function. Frequent seizures manifested predominantly by facial twitching were apparent. The liver edge was palpable $2.5 \mathrm{~cm}$ below the costal margin and she had normal female genitalia. Cardiovascular examination was normal except for tachycardia (104 beats per minute). She had no distinct dysmorphic features and, in particular, there was no evidence of maxillary retrusion, pouting mouth, or lax finger joints, although slight hirsutism was apparent.

Investigations

CT and MRI scans showed generalised cerebral and brainstem atrophy and delayed myelination (MRI), while an EEG showed multifocal spikes and sharp waves. Brainstem evoked responses also suggested a brainstem abnormality with an increased interpeak latency between waves $I$ and V. Visual evoked responses, EMG, and nerve conduction studies were within normal limits, while a muscle biopsy showed normal morphology. She had a normal 46,XX karyotype.

Analysis of serum electrolytes, lactate, ammonia, white cell enzymes, TORCH screen for intrauterine infections, galactose-l-phosphate uridyl transferase, thyroid function, long chain fatty acids, blood picture, and amino acids was non-contributory. Urine screen for heavy metals, mucopolysaccharides, and sugars was normal. CSF examination showed a slight rise in protein at $0.88 \mathrm{~g} / 1$ (normal=less than $0.4 \mathrm{~g} / \mathrm{l}$ ), but the lactate was normal. On a skeletal radiographical survey, there

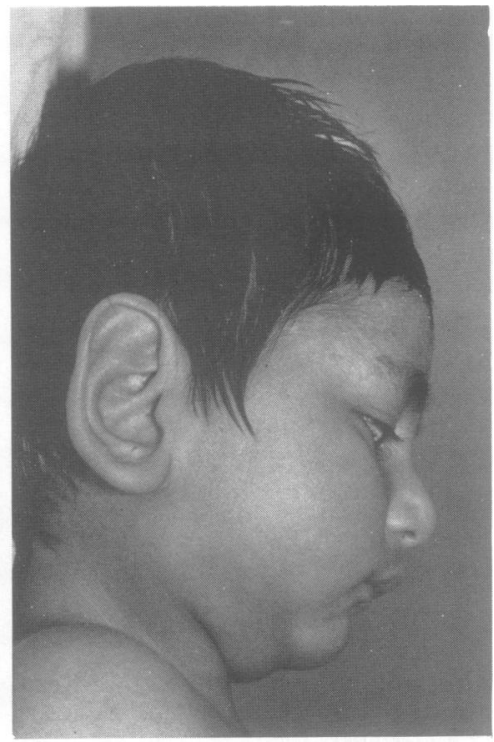


TABLE 1 Summary of clinical findings.

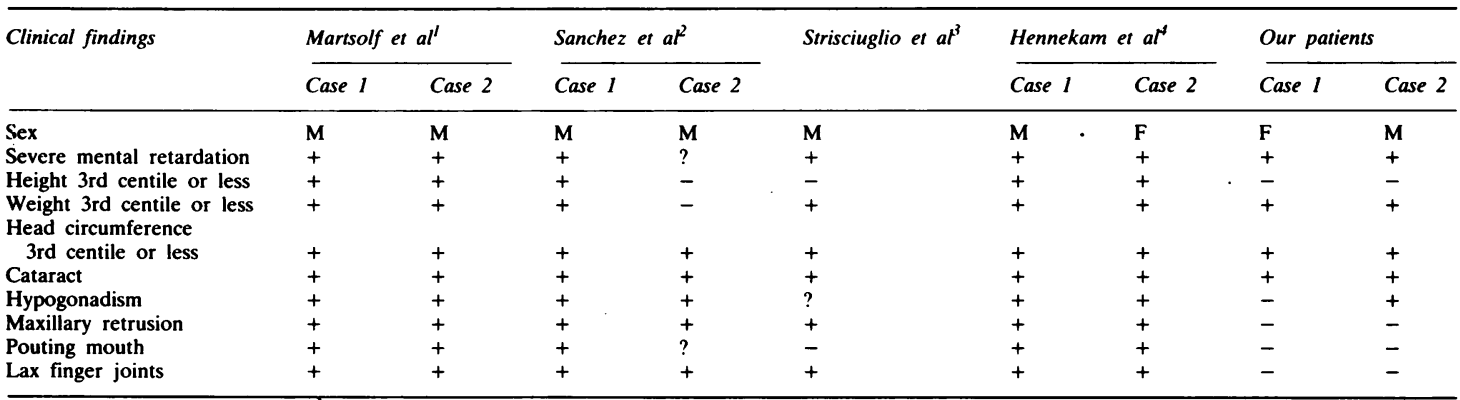

was osteoporosis with growth arrest lines present at the metaphyses. Echocardiography showed a dilated left ventricle which contracted poorly with a shortening fraction of $16 \%$, suggesting a cardiomyopathy.

\section{CASE 2}

The fourth child in the family, a male (IV.4, fig 3), was born at term after a normal pregnancy and delivery. His birth weight was $3200 \mathrm{~g}$ and there were no problems in the neonatal period. At the age of six months, it was apparent that he had poor vision with cataracts, marked hypotonia, minimal head control, and exaggerated tendon reflexes. There were undescended testes. He had slight hirsutism but no evidence of maxillary retrusion, pouting mouth, or lax finger joints.

When reviewed at nine months of age, his head circumference $(40 \mathrm{~cm})$ was $3 \mathrm{~cm}$ below the $3 \mathrm{rd}$ centile, while his weight $(7.7 \mathrm{~kg})$ was on the $3 \mathrm{rd}$ centile and his length $(71 \mathrm{~cm})$ was on the 25 th centile. By 18 months of age, his head circumference was $4.5 \mathrm{~cm}$ below the 3rd centile. He was still hypotonic but appeared to have visual attention after surgical removal of the cataracts. He died 12 months later at the age of two and a half years owing to renal failure secondary to cardiac failure. A necropsy was not performed.

\section{Investigations}

A CT scan showed generalised cerebral atrophy. He had a normal 46,XY male karyotype. Blood urea, calcium, phosphate, and alkaline phosphatase were normal. Urine screen for amino and organic acids, reducing substances, and mucopolysaccharides was non-contributory.

\section{Discussion}

There have been to date a small number of families with microcephaly, congenital cataracts, mental retardation, and hypogonadism to which the eponym Martsolf's syndrome has been attached ${ }^{1-4}$ (table 1). The criteria as outlined above are distinct and would be regarded by most dysmorphologists as being good handles for a diagnosis. The combination of microcephaly, mental retardation, and cataracts occurs in a number of conditions, many of

TABLE 2 Differential diagnosis.

\begin{tabular}{lll}
\hline Clinical findings & $\begin{array}{l}\text { Martsolfs } \\
\text { syndrome }\end{array}$ & $\begin{array}{l}\text { Smith-Lemli-Opitz } \\
\text { syndrome }\end{array}$ \\
\hline Mental retardation & + & + \\
Short stature & + & + \\
Microcephaly & + & + \\
Cataract & + & + \\
Sypogondrome & + & + \\
Ptosis & - & + \\
Narrow forehead with temporal narrowing & - & + \\
Anteverted nares & - & + \\
Postaxial polydactyly & - & + \\
Syndactyly of second and third toes & - & + \\
Cleft palate & - & + \\
Persistent hyperplastic primary vitreous & - & - \\
\hline
\end{tabular}


which can be excluded on the basis of additional skin or limb abnormalities, such as in Roberts's pseudothalidomide syndrome or incontinentia pigmenti. The normal karyotype in our cases excluded chromosomal abnormalities and there was no evidence of a congenital rubella embryopathy.

When hypogonadism occurs in addition to microcephaly, mental retardation, and cataracts, only a small number of syndromes needs to be considered in the differential diagnosis. One is Smith-LemliOpitz syndrome, ${ }^{5}$ but cataracts in that syndrome are rare and, looking at table 2 , there are more differences than similarities. The other condition that needs excluding is the oculopalatocerebral syndrome, ${ }^{6}$ in which a cleft palate and a persistent hyperplastic primary vitreous with microphthalmia are cardinal features, but which are absent in Martsolf's syndrome.

Lowe's syndrome, ${ }^{7}$ which is $\mathrm{X}$ linked, was excluded by finding a normal amino acid pattern and galactosaemia was also biochemically excluded.

A number of other minor features were originally reported by both Martsolf $e t$ al $^{1}$ and Sanchez et al. ${ }^{2}$ These include brachycephaly, lax finger joints, talipes valgus, a pouting mouth, and maxillary retrusion with slight hirsutism, but these are difficult to evaluate. The facial features in the two sibs in this report are not distinct. Both are clearly microcephalic and have small jaws with slight hirsutism, but it remains uncertain whether facial dysmorphic features are useful in helping the clinician to establish the diagnosis.

It is of interest that one of the sibs had a cardiomyopathy and the other died from cardiac failure, although the exact nature of the lesion was not elucidated. The combination of cataracts, a cardiomyopathy, and nephronophthisis has been described in mitochondrial cytopathy. ${ }^{8}$ The child described in that report had typical features of a mitochondrial myopathy on muscle biopsy, whereas case 1 in our family had a muscle biopsy which was normal. Microcephaly in the neonatal period would also be very unusual in mitochondrial disease.

In summary, we report a brother and sister pair with features of Martsolf's syndrome to indicate its recessive nature and also to suggest that, in view of the presence of a cardiomyopathy in one sib and cardiac failure in the other sib, the spectrum is either larger than first anticipated or alternatively that the condition described in this paper is a separate genetically determined entity.

The authors thank Dr G McEnery, Whipps Cross Hospital, for his assistance in the preparation of this report.

References
1 Martsolf JT, Hunter AGW, Haworth JC. Severe mental
retardation, cataracts, short stature and primary hypogonadism
in two brothers. Am J Med Genet $1978 ; 1: 291-9$.
2 Sanchez JM, Barreiro C, Freilij H. Two brothers with Martsolf's
syndrome. J Med Genet 1985;22:308-10.
Strisciuglo P, Costabile M, Esposito M, Di Maio S. Martsolf's
syndrome in a non-Jewish boy. J Med Genet 1988;25:267-9.
4 Hennekam RCM, van de Meeberg AG, van Doorne JM, et al.
Martsolf syndrome in a brother and sister: clinical features and
pattern of inheritance. Eur J Pediatr $1988 ; 147: 539-43$.
Lowry RB. Variability in the Smith-Lemli-Opitz syndrome:
overlap with the Meckel syndrome. Am J Med Genet 1983;14:
$429-33$.
6 Frydman M, Kauschansky A, Leshem I, Savir H. Oculo-palato-
cerebral dwarfism: a new syndrome. Clin Genet 1985;27:414-9.
7 Smith DW, ed. Recognizable patterns of human malformation.
Philadelphia: Saunders, 1982:158.
8 Donaldson MDC, Warner AA, Trompeter RS, et al. Familial
juvenile nephronophthisis, Jeune's syndrome and associated
disorders. Arch Dis Child $1985 ; 60: 426-34$.

Correspondence to Dr M Baraitser, Department of $\dot{\sigma}$ Clinical Genetics, The Hospitals for Sick Children, Great Ormond Street, London WC1N 3JH.

\title{
Dominant inheritance of Scheuermann's juvenile kyphosis
}

\author{
A FINDLAY*, A N CONNER†, AND J M CONNOR* \\ *Duncan Guthrie Institute of Medical Genetics, Yorkhill Hospitals, Glasgow; and †Department of \\ Orthopaedic Surgery, Royal Hospital for Sick Children, Glasgow.
}

SUMMARY We report a family in which Scheuermann's juvenile kyphosis is present in three successive generations with male to male transmission. This provides further evidence for autosomal dominant inheritance in at least some families with this condition.

Received for publication 15 August 1988.

Revised version accepted for publication 22 November 1988.
Scheuermann's disease (MIM18144), or spinal osteochondrosis, although probably first recognised $\stackrel{0}{\leftarrow}$ by Stafford ${ }^{1}$ in 1832 , was described by Scheuermann in $1920 .^{2}$ It is a condition where there is an abnormal and fixed thoracic kyphosis of unknown aetiology that develops around the time of puberty. Associated with this physical deformity, Scheuermann ${ }^{2}$ found $\stackrel{\odot}{\mathbb{Q}}$ radiographical evidence of thoracic vertebral wedging 2 and irregularities of the growth plates of the affected

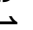

